\title{
sciendo
}

\section{COMPOSITION OF VOLATILE COMPOUNDS IN HEAT-TREATED MEAT FROM POLISH NATIVE SHEEP BREEDS USING HS-SPME-GC/MS - CHEMOMETRIC CLASSIFICATION BASED ON BREED AND AGE*}

\author{
Robert Gąsior ${ }^{1 \star}$, Aldona Kawęcka², Krzysztof Wojtycza ${ }^{1}$, Jacek Sikora² \\ ${ }^{1}$ Central Laboratory, National Research Institute of Animal Production, \\ 32-083 Balice n. Kraków, Poland \\ ${ }^{2}$ Department of Sheep and Goat Breeding, National Research Institute of Animal Production, \\ 32-083 Balice n. Kraków, Poland \\ •Corresponding author: robert.gasior@izoo.krakow.pl
}

\begin{abstract}
In order to characterize the volatile compounds composition of lamb meat, 3 groups of baked leg muscle samples from two Polish native sheep breeds: Świniarka aged 9 months (S9), Wrzosówka aged 9 months (W9), and Wrzosówka aged 7 months (W7), were analyzed by HS-SPME-GC/MS, followed by multivariate statistics comprising the F-ratio method for variables pre-selection, and PCA-LDA analysis. Ninety seven volatile compounds were determined, out of which 74 were identified. The largest classes of volatile compounds were aldehydes and furans followed by alcohols, hydrocarbons, ketones, and sulfur and nitrogen compounds. Statistically significant differences between the S9, W9, and W7 groups were observed for 11 volatiles, i.e.: pentanal; hexanal; 1,3-octadiene; benzaldehyde; 3-ethyl-2-methyl-1,3-hexadiene; 3-octen-2-one; 2-octenal; 2-hexylfuran; tetradecanal; pentadecanal; hexadecanal. The HS-SPME-GC/MS method coupled with chemometrics, based on the relative intensity spectral data of these volatiles, proved to be an effective tool for the discrimination of lambs according to breed and age. The classification accuracy value for the S9, W9, and W7 groups was $100 \%$.
\end{abstract}

Key words: native breeds, sheep meat, SPME-GC/MS, chemometrics, Fisher's ratio

\section{Competing interests}

The authors declare that they have no conflict of interest.

Modern farming methods and the production of meat and other animal products have, on the one hand, lowered prices for consumers, yet on the other hand have led

\footnotetext{
*This study was funded by statutory activity no. 01-13-04-11.
} 
to the market for food becoming less varied in taste and aroma. The increasingly widespread ecological awareness of consumers is strengthening the ever-increasing tendency towards the consumption of food products from animals that are kept under natural conditions and have free access to open areas and grasslands, as well as being given organic feed. The growing demand for high-quality organic food products, including those that come from native breeds, should increase the consumption of meat, cheese, and other such products. Perfectly suited to these needs are products derived from native sheep breeds, maintained mostly with permanent access to pasture. The Wrzosówka and Świniarka used in this study are old Polish sheep breeds from which the meat is considered a delicacy, and many consumers compare it to game meat due to its unique taste, aroma, and color. Lamb meat, just like sheep's milk products, is considered a functional food, namely one that has a beneficial effect on the human body beyond its nutritional function. The health-promoting properties of sheep products are associated, among others, with the fatty acid profile of intramuscular fat, including the high content of unsaturated fatty acids and conjugated linoleic acid (Kawęcka et al., 2017).

The flavor of meat depends on the content of volatile compounds, and characterizing them is particularly interesting, though not easy. The basic technique used in this field is gas chromatography-mass spectrometry, often coupled with headspacesolid phase microextraction. This technique allowed for determining the volatiles in cheese (Majcher et al., 2015), honey (Dymerski et al., 2013), nuts (Kiefl and Schieberle, 2013), and teas and herbs (Lv et al., 2015). It is also possible to analyze volatile compounds in meat (Soncin et al., 2007; Ba et al., 2010). However, as for tests of volatile substances in meat from breeds prevalent in Poland, it is difficult to find any data concerning this topic. The preliminary studies on this subject that were carried out comprised the analysis of these compounds in five types of meat, i.e. pork, beef, mutton, nutria meat and broiler chicken breasts (Gąsior and Wojtycza, 2016), as well as in capon and cockerel meat (Calik et al., 2017). It should be emphasized that apart from genetic factors, the composition of volatile compounds is also associated with the feeding, method of maintenance, quality and type of fodder (Elmore et al., 2000; Nuernberg et al., 2005; Scollan et al., 2006), the ripening of meat in a freezer, and the product processing temperature. Volatile compounds composition of meat is also influenced by the age of the animal (Ba et al., 2012).

Chromatographic analysis of complex biological matrices, including the determination of volatile compounds in meat, produces a large number of variable data. That is why, in order to differentiate the sample groups, multivariate statistical techniques have often been used. In this case, targeted (Nicolotti et al., 2013), or non-targeted analyses (Majcher et al., 2015) are applied. A comparison of samples can be based on a few specific substances, groups of substances, or all compounds. With targeted techniques, the accuracy of the quantitative assay is important for profiling the volatile compounds. Accuracy is ensured by the use of standards, e.g., stable isotope dilution assays, standard addition, and external standard approaches. In turn, with non-targeted techniques, mass spectra that could contain a large number of data concerning the type and intensity of $\mathrm{m} / \mathrm{z}$ fragment ions are usually used. To improve the data interpretation capability, firstly the data preprocessing is needed. For this pur- 
pose a pre-selection of the most differentiating variables by Fisher's ratio (F-ratio) method may be used (Marney et al., 2013), followed by an applicable chemometric process. The common statistical models are: principal component analysis (PCA) and linear discriminant analysis (LDA), together with the classification of samples (Majcher et al., 2015).

The aim of the present study was the characterization of the meat of three lamb groups of two Polish native sheep breeds, the Świniarka and Wrzosówka, based on volatile compounds composition, and checking the possibility of discriminating the groups by headspace-solid phase microextraction-gas chromatography-mass spectrometry (HS-SPME-GC/MS) analysis of volatile compounds coupled with chemometrics.

\section{Material and methods}

\section{Materials}

Acetone ( $\geq 99.9 \%)$, 1-octanol ( $\geq 99 \%)$, toluene (99.8\%), acetaldehyde ( $\geq 99.5 \%)$, 2,3-butanedione (analytical standard), acetic acid ( $\geq 99.5 \%)$, and 2-methylthiophene (98\%), 1-octene (98\%), hexanal (98\%), furfural (99\%), (E)-2-hexenal (98\%), 2-heptanone (98\%), heptanal ( $\geq 95 \%)$, dimethyl sulfone $(98 \%), \alpha$-pinene (analytical standard), dimethyl trisulfide ( $\geq 98.5 \%)$, 1-octen-3-ol (98\%), 1-octen-3-one $(96 \%)$, thiophene-2-carboxaldehyde (98\%), 2-acetylthiazole $(\geq 99 \%)$, limonene (analytical standard), nonanal (95\%), (E,E)-2,4-decadienal (89\%), decanal ( $\geq 98 \%)$, (E)-2-undecenal $(\geq 90 \%)$ were purchased from Sigma-Aldrich Corp., Merck group (Poznań, Poland). The $n$-paraffin mixes (3 packages): $\mathrm{C} 5$ to $\mathrm{C} 15$, and $\mathrm{C} 10, \mathrm{C} 12, \mathrm{C} 14, \mathrm{C} 16$, and C18, C20, C22, C24 were purchased from Supelco, Merck group (Poznań, Poland).

\section{Experimental design}

The experiment involved 18 ram lambs of the Wrzosówka and Świniarka native sheep breeds, which were selected from conservation herds belonging to the National Research Institute of Animal Production. All the animals were 6 months of age, with the initial body weight of the lambs at $16 \mathrm{~kg}$. The animals were maintained in a semi-intensive system: they received meadow hay and straw ad libitum as well as about $0.4 \mathrm{~kg}$ of concentrate per animal. At the age of 7 months, 6 lambs of the Wrzosówka breed were slaughtered. The rest of the animals were maintained to 9 months of age. As a result, 18 animals in 3 groups of 6 animals were obtained. The first group was Świniarka aged 9 months (S9), Wrzosówka aged 9 months (W9), and Wrzosówka aged 7 months (W7). The carcasses were chilled for $24 \mathrm{~h}$ at $4^{\circ} \mathrm{C}$. Slaughter analysis was performed according to the procedure used at the National Research Institute of Animal Production.

\section{Meat samples}

For volatile compounds analysis, $18 \mathrm{ca} .200 \mathrm{~g}$ leg muscle (m. biceps femoris) samples (one sample from each of the 18 animals from the S9, W9 and W7 groups) 
were taken and cut into smaller pieces. Next, these were vacuum-packed in $100 \mathrm{~g}$ portions into polyamide/polyethylene bags, and stored at $-80^{\circ} \mathrm{C}$.

\section{Sample preparation and analysis}

An unthawed $\left(-80^{\circ} \mathrm{C}\right)$ and previously cut ca. $10 \mathrm{~g}$ sample was processed at a low temperature by liquid nitrogen, and next homogenized and transferred into a $20 \mathrm{ml}$ vial sealed with an aluminum crimp cap and PTFE/silicon septum. The prior portioning of the sample into small pieces and, next, using the liquid nitrogen was extremely important since it allowed the material to be kept frozen until the heat treatment and analysis started. Next, the thawed sample was baked in the same sealed vial $\left(170^{\circ} \mathrm{C}\right.$, $35 \mathrm{~min}$ ) and analyzed by HS-SPME-GC/MS using the gas chromatograph mass spectrometer GCMS-QP 2010 Plus (Shimadzu, Duisburg, Germany) and 50/30 $\mu \mathrm{m}$ DVB/CAR/PDMS fiber (Supelco, Merck group, Poznań, Poland). Two GC columns (Phenomenex; Shim-Pol, Izabelin, Poland), one non-polar (Zebron ZB-5MSi 30m $\mathrm{x} 0.25 \mathrm{~mm}, 0.25 \mathrm{um}$ ) and the other polar (Zebron ZB-Wax $30 \mathrm{~m} \times 0.25 \mathrm{~mm}, 0.25 \mathrm{um}$ ), were used. The sample was injected by the SPME autosampler Combi Pal System, AOC-5000 (Shimadzu, Duisburg, Germany), with an equilibration time and temperature of $30 \mathrm{~min}$ and $50^{\circ} \mathrm{C}$, respectively, and exposition time and temperature of $15 \mathrm{~min}$ and $50^{\circ} \mathrm{C}$, respectively. The sample compounds were desorbed in the splitless port at $240^{\circ} \mathrm{C}$ for $2 \mathrm{~min}$. The analysis conditions were as follows: helium flow (He,

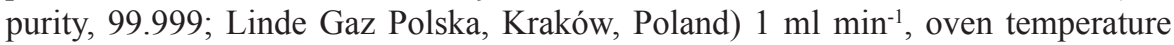
$37^{\circ} \mathrm{C}(10 \mathrm{~min})$, then increased to $132^{\circ} \mathrm{C}\left(4^{\circ} \mathrm{C} / \mathrm{min}\right)$ and $240^{\circ} \mathrm{C}\left(8^{\circ} \mathrm{C} / \mathrm{min}\right)$. The total time of the analysis was $60 \mathrm{~min}$. The quadrupole electron ionization $(70 \mathrm{eV})$ mass spectrometer was operated in full scan mode in a range of $35-450 \mathrm{~m} / \mathrm{z}$ (416 ions). The temperature of the ion source was $250^{\circ} \mathrm{C}$. A blank sample (analysis from an empty vial using the same fiber, under the same conditions as for the meat sample) was also analyzed, and then the extraneous compounds were excluded during calculation of the results. The autosampler rack was cooled to about $+3^{\circ} \mathrm{C}$. To eliminate analytical trends effects disturbing the results, the sample vials were placed in a rack in a staggered manner (Calik et al., 2017). This way of proceeding was the next crucial step of the whole analysis process.

\section{Chromatogram integration and peak identification}

The substances were identified (by mass spectra libraries: NIST08, NIST08s, FF NSC1.3, by RI - retention index, or by $\mathrm{S}$ - standards), and additionally, literature references were noted. RI data were retrieved from a reference database of the National Institute of Standards and Technology and compared - based on analyses of $n$-paraffins - with values calculated as Kovats' RI for isothermal analysis, and as Van den Dool and Kratz RI for using temperature ramp. For quantitation, the methyl hexanoate (internal standard) was used (Sigma-Aldrich, Merck Group, Poznań, Poland), and the results were expressed as ng per $1 \mathrm{~g}$ of sample. The total area of all the peaks was about $5^{\prime} 10^{8}$ area units, and these peaks of compounds whose area was more than 9,000 area units were integrated. Statistically significant differences between the experimental groups of lambs were found using one-way ANOVA (Statgraphics ${ }^{\circledR}$ Centurion XVI, Statpoint Technologies, Inc.; Gambit, Kraków, Poland). 


\section{Chemometrics}

The possibility of differentiation between the 3 lamb groups, S9, W9, and W7, based on 11 compounds was investigated (total samples in each group, $n=6$ ). For this purpose, a chemometric analysis for relative intensity spectral data of these compounds was performed. 4,576 relative $\mathrm{m} / \mathrm{z}$ ion intensities were the variables used in chemometrics (416 relative intensities of mass spectrum ions $\times 11$ volatile compounds). These data were logarithmically transformed, followed by the pre-selection of variables using the F-ratio method. Next, PCA was used, whereby the number of variables was reduced to the principal components using Cattell's scree test in order to avoid the classification model overfitting. Then, LDA was performed and the classification accuracy was calculated by cross validation. The PCA-LDA analysis was executed using Statgraphics ${ }^{\circledR}$ Centurion XVI equipped with a multivariate statistics package (Statpoint Technologies, Inc.; Gambit, Kraków, Poland). The F-ratio value was computed adopting statistical functions in Microsoft Excel $^{\mathbb{R}}$.

\section{Results}

\section{Volatile compounds identification}

Ninety seven volatile compounds were determined by HS-SPME-GC/MS, out of which 74 were fully identified (Table 1). Volatile compounds were considered fully identified if they were confirmed by either an external standard or by using retention indices calculated on both the non-polar and the polar column. However, some of the compounds (not presented in Table 1) were tentatively indicated, i.e., 2-pentanone, 3-methyloctane, 3-heptanol, 3-ethylcyclopentanone, 3-ethyloctane, 3-methylnonane, 2,2,7,7 (or 2,2,4,4)-tetramethyloctane, 2-ethylhexanol, 6-nonenal, 5-undecen, 9-methyl-, undecyne, 3,5-dimethyl-1,2,4-trithiolane, 3-nonen-2-one, dimethyl tetrasulfide, 3-dodecyne, 2-decen-1-ol, dodecanol, tridecanal, 1 (or 3 or 5)-octadecene, 3,7,11,15-tetramethyl-2-hexadecene, hexadecanol, heptadecanal, and octadecanal. Among the 74 fully identified volatile compounds, significant differences between the S9, W9, and W7 groups for 11 volatiles were found (Table 1). Five volatile compounds revealed highly significant $(\mathrm{P} \leq 0.01)$ and six other ones only significant $(\mathrm{P} \leq 0.05)$ differences between the lamb groups.

\section{Classes of volatile compounds}

In this work on lamb meat, 7 classes of volatile compounds are presented in Figure 1. The classes of volatile compounds did not significantly differentiate lambs from the S9, W9 and W7 groups. In turn, the 10 most abundant identified substances (ng/g on average from the 3 lamb groups) are specified in Figure 2. 


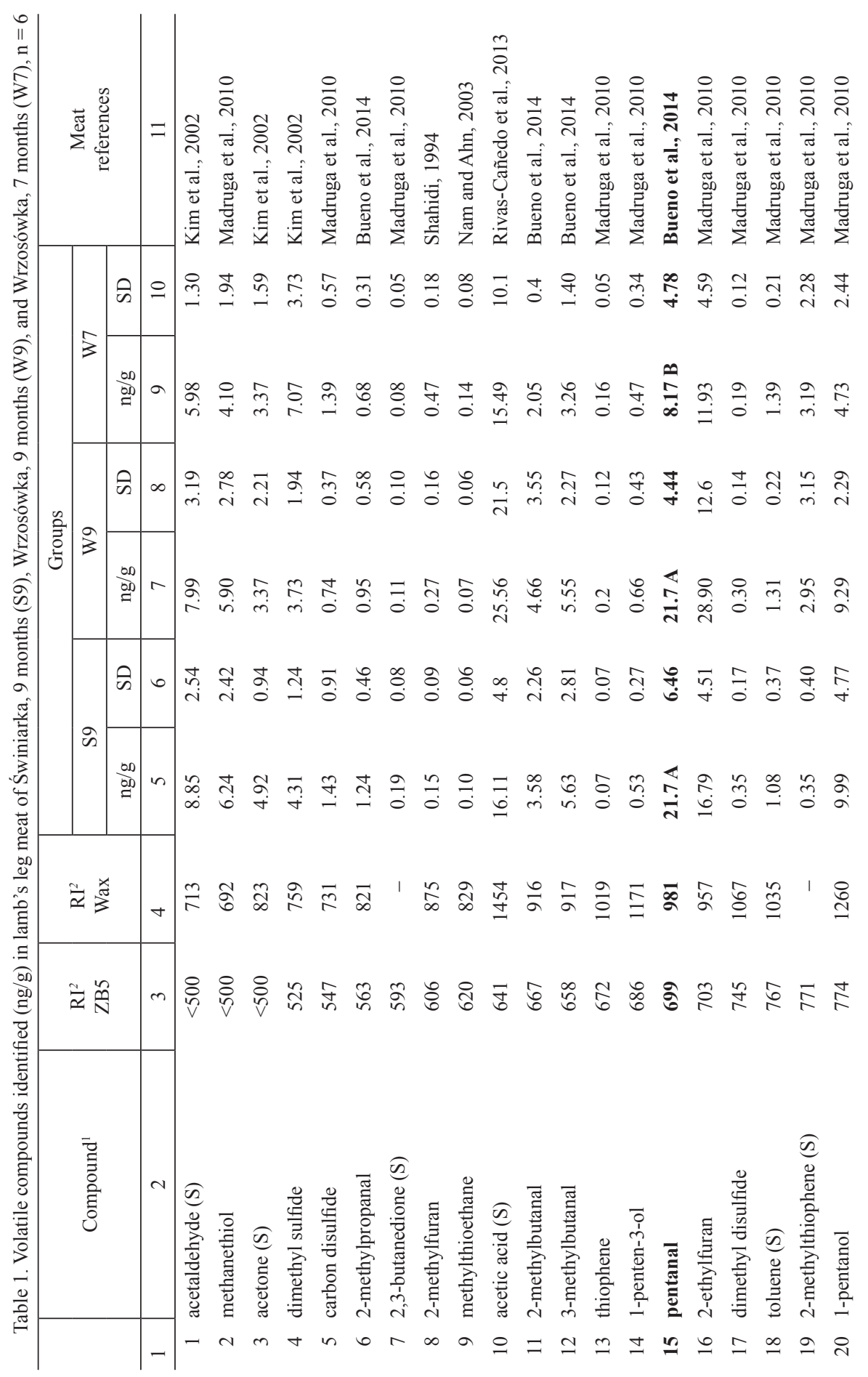




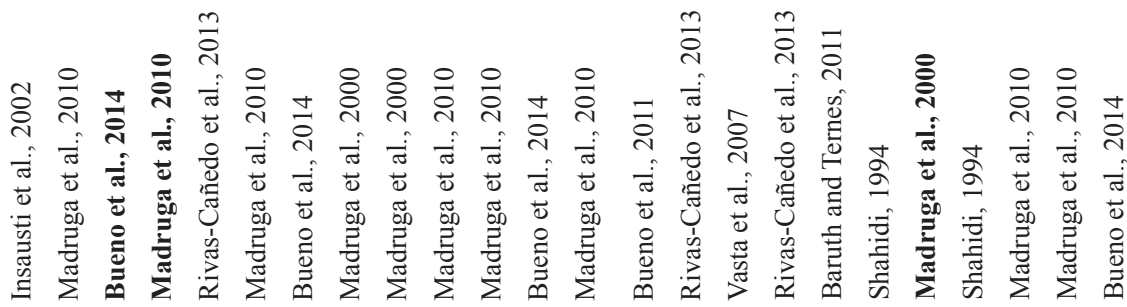

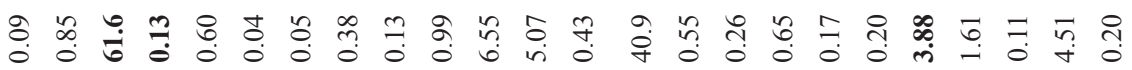

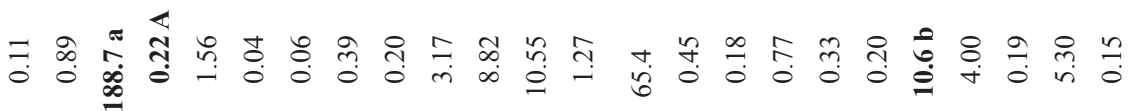

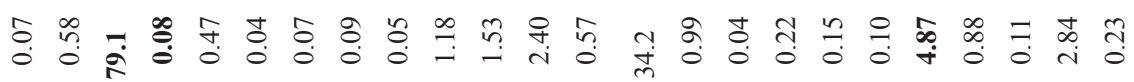

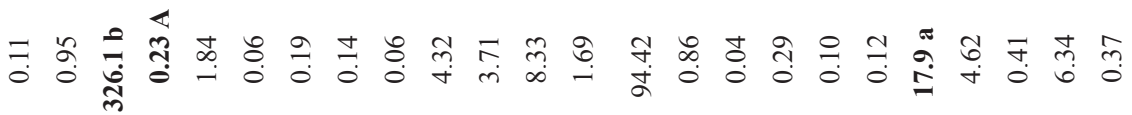
范 તై

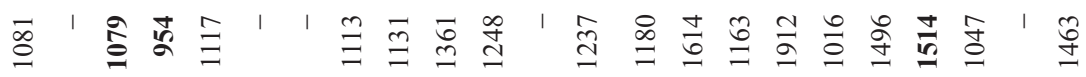

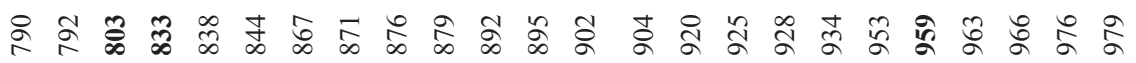

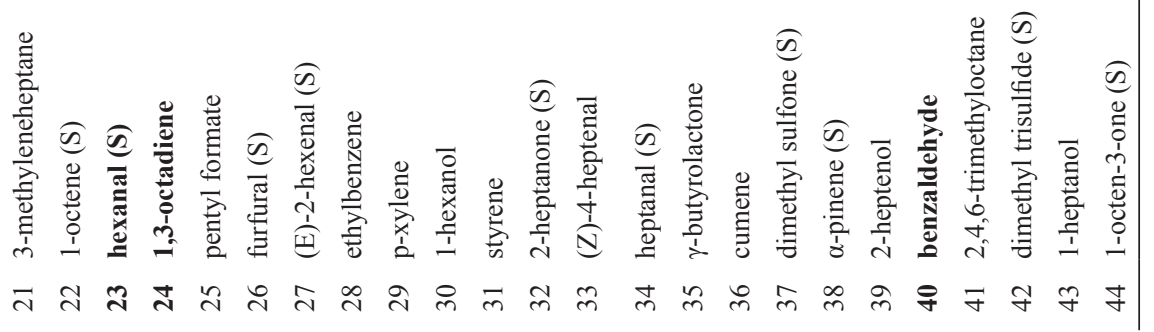




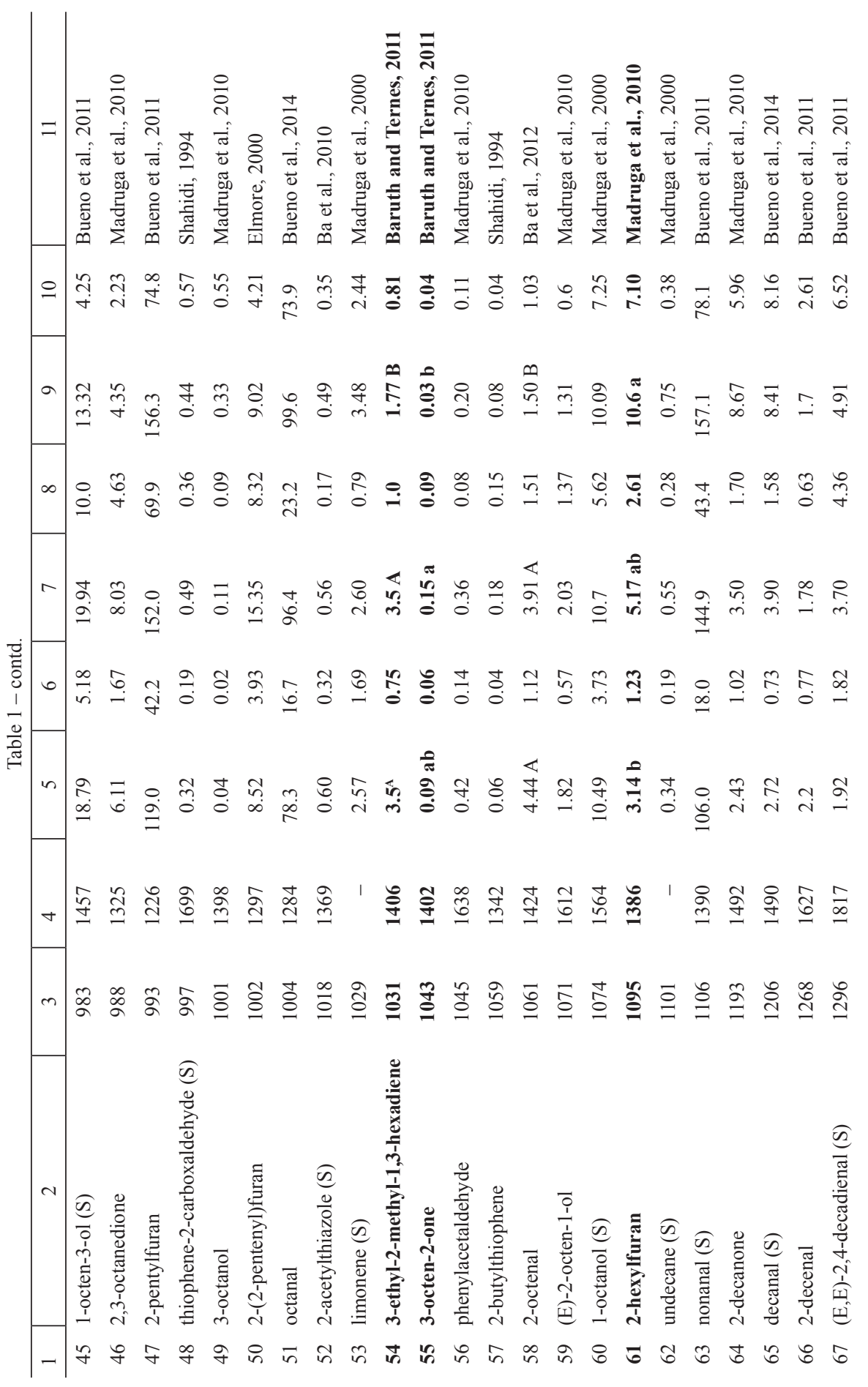




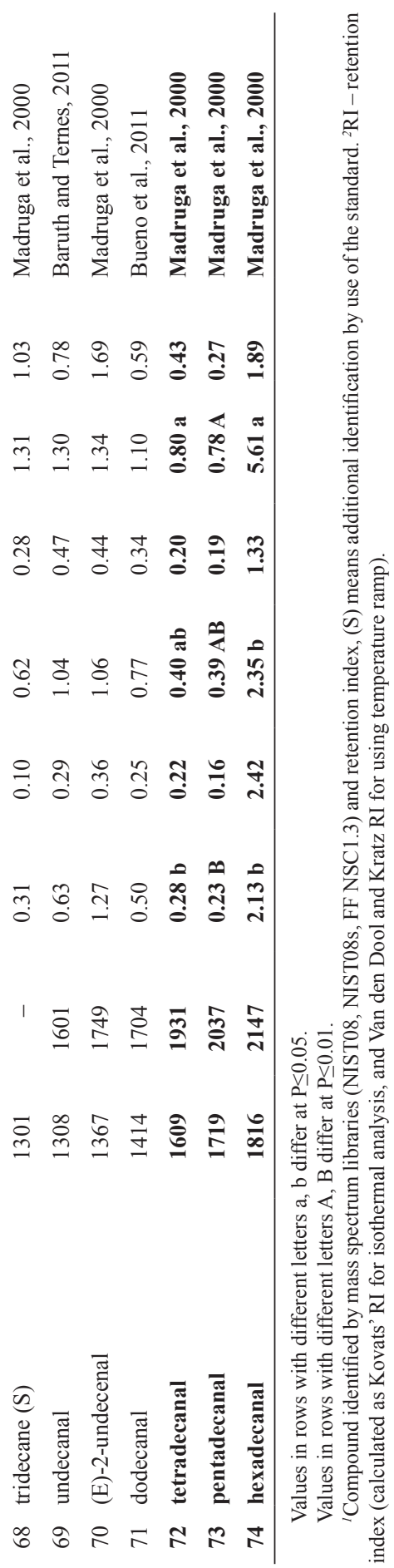




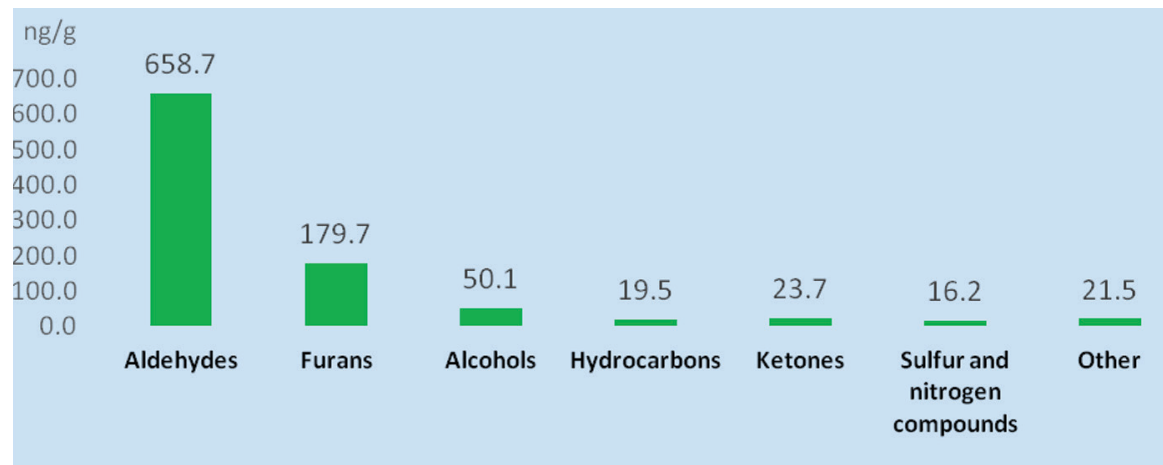

Figure 1. Classes of volatile compounds in Świniarka and Wrzosówka lambs' leg meat. Average in ng/g of the S9, W9, and W7 lamb groups $(\mathrm{n}=18)$

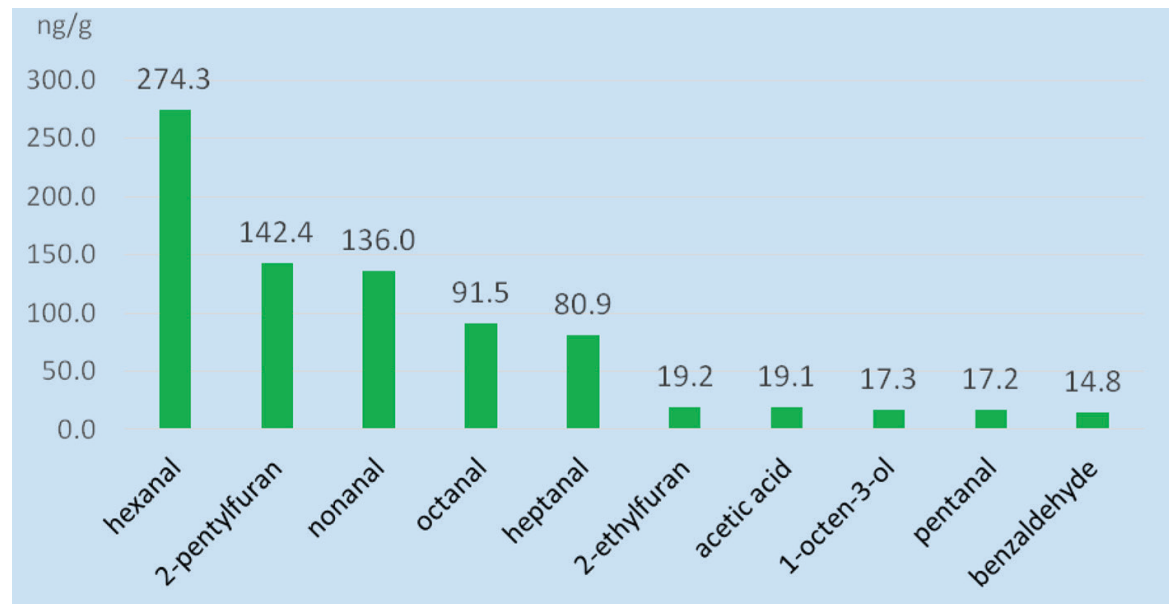

Figure 2. The 10 most abundant (ng/g) from 74 identified volatile compounds in the S9, W9, W7 groups (ng/g on average, $\mathrm{n}=18$ )

Scatterplot

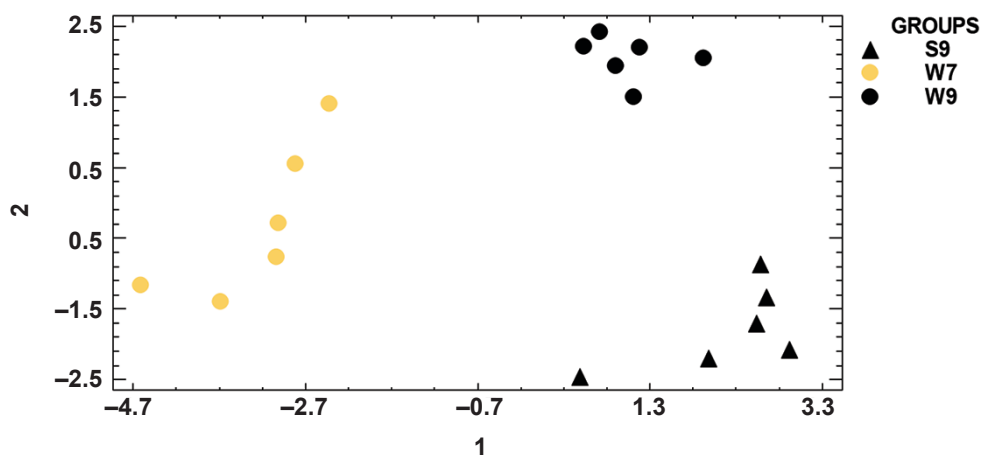

Figure 3. PCA-LDA scatter plot of relative intensity spectral data for 11 volatile compounds, after data pre-selection by F-ratio method 


\section{Chemometrics}

A PCA-LDA scatter plot of relative intensity spectral data for 11 volatile compounds is shown in Figure 3. The results of discriminant analysis revealed a very good classification accuracy amounting to $100 \%$.

\section{Discussion}

\section{Volatile compounds identification}

The tentatively identified compounds were not confirmed either by an external standard or by the second column, although they have been previously identified in the literature in various types of meat (Pongsetkul et al., 2016; Lorenzo et al., 2014; Rivas-Cañedo et al., 2013; Kang et al., 2013; Acevedo et al., 2012; Baruth and Ternes, 2011; Ba et al., 2010; Madruga et al., 2010; Narváez-Rivas et al., 2010; Vasta et al., 2007; Lee et al., 2003; Machiels et al., 2003; Madruga et al., 2000; Shahidi, 1994). On the other hand, methional (3-methylsulfanylpropanal), sometimes detected in grilled lamb meat (Resconi et al., 2010), was not identified, possibly due to being covered by a large heptanal peak. Among these volatiles, odors of 2-pentanone (sweet, fruity) dimethyl tetrasulfide (cabbage), and 2-ethylhexanol (resin, flowery, green) were described in a study on goat meat grilled for 5 to 9 minutes (Madruga et al., 2010). In turn, among the 74 identified volatile compounds, the odor-active compounds in meat, according to Madruga et al. (2010) were as follows: methanethiol (rotten, eggs), carbon disulfide (sulfury, fruity, burnt, cabbage), 2-acetylthiazole (roasted, nutty, popcorn, meaty), 2-pentylfuran (fruity, green, sweet, pungent), limonene (lemon, orange), 3-octanol (nutty, sulfury), pentanal (pungent, almond), benzaldehyde (roasted pepper, nutty), (E)-2-hexenal (fresh cut grass), (Z)4-heptenal (cream like, fatty, rancid, crabby), 2-decenal (chicken fat, fried notes). The next compounds (Resconi et al., 2010) were: 2-methylbutanal (sweet, mushroom), hexanal (green, floral), octanal (lemon, floral), decanal (roast meat, fried potato), 2,4-decadienal (burnt meat, rancid), 2,3-butanedione (sweet, dairy), 1-octen-3-one (mushroomy, earthy), and, according to Ba et al. (2012), who presented the aroma characteristics of volatile compounds in cooked meat, dimethyl trisulfide (fragrant, musty, roasted, rubbery), dimethyl disulfide (moldy, pungent, rubbery, onion-like), heptanal (fruity, fatty, sweet, oily), nonanal (sweet, fatty, green), undecanal (sweet, pungent, green), 3-methylbutanal (meaty, fish, rotten, aldehyde, valeric acid, fatty), phenylacetaldehyde (sweet, honey), (E)-2-undecenal (sweet, fruity, fatty), 2-decanone (fruity, musty), 2-heptanone (citrus, grapefruit, floral, cheese), 1-pentanol (mild odor, fuel oil, fruit, balsamic), 1-hexanol (woody, cut grass, chemical-winey, fatty, fruity), 1-heptanol (fragrant, woody, oily, green, fatty, winey, sap), 1-octanol (penetrating aromatic odor, fatty, waxy, citrus, oily), 1-octen-3-ol (mushroomy), (E)-2octen-1-ol (green citrus), styrene (penetrating odor, sweet), tridecane (alkane). Apart from that, also other important compounds which create the major aroma of food were found in sheep meat (Dunkel et al., 2014): dimethyl sulfide (sulfurous, onion, cabbage), 2-methylpropanal (fresh, floral, pungent), acetaldehyde (pungent, ethereal, 
fruity), acetic acid (pungent, sour), $\alpha$-pinene (fresh, pine, woody), and (E)-2-octenal (fatty, green, herbal).

It is also possible to compare heat-treated meat with raw meat. It is known that more volatiles should be expected in meat after heat treatment because the rise in temperature increases the rate of chemical reactions and promotes the formation of additional substances as a result of Maillard processes. This is confirmed by a comparison of results regarding raw (16 substances, Karabagias, 2018) and heat-treated (74 compounds, this work) lamb meat. In addition, in the present study, a large share of aldehydes, mostly hexanal, which is formed due to oxidation of unsaturated omega-6 fatty acids, is noticeable (Karabagias, 2018). It can also be seen that many of the compounds found in sheep meat are common, regardless of whether this meat is raw or processed. According to research conducted by Karabagias (2018) and in the present work, these were: 1-pentanol, 1-hexanol, 1-octen-3-ol, 1-heptanol, 1-octanol, hexanal, heptanal, octanal, nonanal, toluene, xylene, carbon disulfide.

\section{Volatiles differentiating the lamb groups}

It can be seen in Table 1 that five of the volatile compounds visibly differentiated (W7 statistically different from S9 and W9) the lambs by age. These were: pentanal, 3-ethyl-2-methyl-1,3-hexadiene, 2-octenal $(\mathrm{P} \leq 0.01)$, and hexanal and hexadecanal $(\mathrm{P} \leq 0.05)$. Five other volatiles - benzaldehyde, 3-octen-2-one, 2-hexylfuran, tetradecanal, and pentadecanal - did so less clearly. For these compounds, the differences were statistically significant between W7 and only one of the other groups. In turn, only one compound - 1,3-octadiene - differentiated the animals by breed (S9 statistically different from $\mathrm{W} 9$ and $\mathrm{W} 7, \mathrm{P} \leq 0.01)$.

\section{Classes of volatile compounds}

According to a previous study on goat meat (Madruga et al., 2010), the largest classes of volatile compounds were hydrocarbons, aldehydes, alcohols, and ketones. Similar results as in the work of Resconi et al. (2010), who studied grilled 20-dayaged meat from castrated heavy Corriedale lambs, were also obtained in our study, with the greatest share of aldehydes and furans followed by alcohols, hydrocarbons, ketones, and sulfur and nitrogen compounds (Figure 1). Moreover, only some substances were predominant in the total content of all identified volatile compounds. In the present study, the 5 and 10 most abundant volatiles present in the lamb meat (Figure 2) accounted for $75.1 \%$ and $84.2 \%$ of the total content of all volatile compounds, respectively. Among these 10 most abundant substances, aldehydes predominated; there were 6 aldehydes $(614.8 \mathrm{ng} / \mathrm{g}), 2$ furans $(161.7 \mathrm{ng} / \mathrm{g}), 1$ alcohol $(17.3 \mathrm{ng} / \mathrm{g})$, and one carboxylic acid $(19.1 \mathrm{ng} / \mathrm{g})$. In addition, it appears that furans make a great contribution, among them 2-pentylfuran and 2-(2-pentenyl)furan, which are lipid-derived volatile compounds. Elmore et al. (2000) further suggested that 2-ethylfuran and 2-(2-pentenyl)furan are probably derived from the decomposition of DHA and EPA upon cooking. However, taking into account the size of classes, the order appeared as follows: aldehydes ( 24 volatile compounds), hydrocarbons (14 volatile compounds), sulfur and nitrogen compounds (12 volatile compounds, among them one was a sulfur and nitrogen heterocyclic compound - 2-acetylthi- 
azole), alcohols (9 volatile compounds), ketones ( 7 volatile compounds), furans ( 5 volatile compounds), and other (acetic acid, pentyl formate, and $\gamma$-butyrolactone). Far fewer volatiles in classes were observed by Karabagias (2018) in studies on raw sheep meat stored at $4^{\circ} \mathrm{C}$. This author found 4 aldehydes, 4 hydrocarbons, 2 sulfur and nitrogen compounds, 5 alcohols, 1 ketone, and noted an increase in the content of these compounds during storage. The occurrence of fewer volatiles in classes in raw meat could be explained, as previously mentioned, by the influence of temperature on the rate of chemical reactions and by the formation of Maillard compounds.

In the present study, no pyrazines were identified; these may not have been produced in significant enough quantities to allow them to be identified. Most likely this was due to the use of relatively mild thermal processing conditions, whereas pyrazines are formed at higher temperatures (Ba et al., 2012).

In the present work, a large amount of aldehydes and a lower amount of hydrocarbons were found in the baked lamb's leg meat. The origin of hydrocarbons (as well as aldehydes and alcohols) is explained by the thermal degradation of lipids present in the meat after thermal oxidation of the long-chain fatty acids. However, Madruga et al. (2000), studying "mestiço" goat meat, stated that the hydrocarbons do not make an important contribution to the meat aroma because they possess relatively high odor threshold values. In turn, in the study of Resconi et al. (2010) lamb flavor was related to the concentration of 2-heptanone and 1-octen-3-one. Other, also meaningful odor-active carbonyl compounds from lipid oxidation, were decanal and (E,E)-2,4-decadienal. The last one was also identified as one of the most important odorants released during the grilling of the lamb loin. The aroma of this compound stood out because it exceeded more than 1,000 times its odor threshold (Bueno et al., 2014). There is general agreement that sulfur-containing volatiles originate from the degradation of the cysteine and methionine, and are important contributors to the aroma of meat. Sulfides, among them alkyl sulfurous compounds, have a low odor threshold and may contribute to the overall sulfurous aroma notes in cooked goat meat (Madruga et al., 2000). In the present study, in the lamb's leg meat, generally 11 sulfur substances ( 4 sulfides, 1 sulfone, 2 thiols, and 4 cyclic compounds), and 1 cyclic sulfurous and nitrogen compound were confirmed. Among them, the compounds with sulfurous and alliaceous aroma, as dimethyl sulfide, methanethiol, and 2-methylthiophene were in the largest quantities.

\section{Chemometrics}

In this work, a targeted combined with a non-targeted approach of discriminant analysis was applied. The data model for discriminant analysis was created based on the relative intensity spectral data of the 11 chosen compounds. In just a few works concerning the volatile compound composition in meat from lambs and goats, multivariate statistical techniques have been applied for data processing. Therefore, PCA for data visualization was used in the studies on the impact of nutrition (Rivas-Cañedo et al., 2013), meat processing (Kang et al., 2013), and sample processing (Bueno et al., 2011) on volatile composition. No classification analysis was performed in these surveys. The multivariate statistical analysis was applied in some other studies on animal food products. In research on Polish smoked ewes' cheeses, Majcher et 
al. (2015) stated that the first two principal components accounted for $63.6 \%$ of the total variance, and properties of classification ranged - depending on the calculation method and type of product used - between $58.3 \%$ and $100 \%$. In another study on volatile fraction of cheeses (blue-veined) (Berezińska et al., 2007) the first four principal components explained $93.04 \%$ of the total variance $(38.18 \%, 23.62 \%, 16.19 \%$, and $15.05 \%$, respectively). Karpiński et al. (2015) differentiated dry-cured hams and showed that the first two and three principal components accounted for $49.1 \%$ and $67.7 \%$ of the total variance, respectively. Furthermore, results from the study on the sensory quality of półgęsek (Nowicka et al., 2017) show that $45.48 \%$ of the total variability was explained by two principal components. Moreover, Narváez-Rivas et al. (2011) used PCA and LDA analysis in their studies on volatile compounds affected by the diet in Iberian pigs' subcutaneous fat. The authors achieved a very good sample distribution with a $100 \%$ of classification performance. In turn, the study of Calik et al. (2017) on Rhode Island Red (R-11) capons and cockerels shows that the proportion of the total variance explained by the first two principal components was $88.4 \%$, and the classification accuracy, calculated using cross-validation, was $100 \%$.

In the present study, the first two, three, and four principal components accounted for $78.6 \%, 85.9 \%$ and $90.9 \%$ of the total variance, respectively. Studies carried out by the authors of this paper showed more volatile compounds and greater contents of them in heat-treated than in raw meat (data not presented). It appeared that the use of a thermal processing option made it easy to select the variables to create good classification models. The PCA-LDA results reveal a very good discrimination of each of the 3 lamb groups S9, W9, and W7, as it can be seen in Figure 3. The discriminant analysis was effective, all the more so as classification models with an accuracy greater than $80 \%$ are considered satisfactory (Stanimirova et al., 2010).

\section{Conclusions}

Seventy four volatile compounds in lamb's leg meat of two Polish native breeds - the Świniarka and Wrzosówka - were identified in the study. HS-SPME-GC/MS method coupled with chemometrics turns out to be the effective tool for the discrimination of the lambs by breed and age. It is also possible to select the volatile compounds which most differentiate the three lamb groups: Świniarka aged 9 months, Wrzosówka aged 9 months, and Wrzosówka aged 7 months.

\section{References}

A c e ve do C.A., Creix e 11 W., Pavez - B arra C., Sán chez E., A l bornoz F., Young M.E. (2012). Modeling volatile organic compounds released by bovine fresh meat using an integration of solid phase microextraction and databases. Food Bioprocess Technol., 5: 2557-2567.

B a H.V., Olive ro s M.C., Ry u K.S., H w a ng I.H. (2010). Development of analysis condition and detection of volatile compounds from cooked Hanwoo beef by SPME-GC/MS analysis. Korean J. Food Sci. Anim. Resour., 30: 73-86.

B a H.V., Hw ang I., J e ong D., To u s e e f A. (2012). Principle of Meat Aroma Flavors and Future Prospect. In: Latest Research into Quality Control, Dr. Mohammad Saber Fallah Nezhad (ed.); doi: http://dx.doi.org/10.5772/51110, (retrieved September 18, 2019). 
B aruth S., Ternes W. (2011). Volatile compounds of three types of roasted waterflow (duck, mallard and goose) and of roasted duck marinated in orange juice. Arch. Geflugelk., 75: 204-214.

B e r e zińs k a A., B z d u c ha A., O b i e d z iń s ki M.W. (2007). Investigation of the applicability of SPME-GC/MS technique and principal component analysis in the evaluation of a volatile fraction of blue-veined cheeses. Pol. J. Food Nutr. Sci., 57: 7-11.

Bueno M., Resconi V.C., Campo M.M., Cacho J., Ferreira V., Escudero A. (2011). Gas chromatographic-olfactometric characterisation of headspace and mouthspace key aroma compounds in fresh and frozen lamb meat. Food Chem., 129: 1909-1918.

B u en o M., C a m p o M.M., Ca c ho J., Ferreir a V., E s c u d e ro A. (2014). A model explaining and predicting lamb flavor from the aroma-active chemical compounds released upon grilling light lamb loins. Meat Sci., 98: 622-628.

Calik J., Krawczyk J., Św iątkiewicz S., Gąsior R., Wojtycza K., Połtowicz K., O brzut J., P u ch ała M. (2017). Comparison of the physicochemical and sensory characteristics of Rhode Island Red (R-11) capons and cockerels. Ann. Anim. Sci., 17: 903-917.

Dunkel A., S te inhaus M., Kot thoff M., Nowak B., Krautwurst D., Schieberle P., H o fma n n T. (2014). Nature's chemical signatures in human olfaction: a foodborne perspective for future biotechnology. Angew. Chem. Int. Ed. Engl., 53: 7124-7143.

Dymerski T., Chmiel T., Mostafa A., Śliwińska M., Wiśniewska P., Wardenck i W., N a m i éśn i k J., Gór e c ki T. (2013). Botanical and geographical origin characterization of Polish honeys by headspace SPME-GC $\times$ GC-TOFMS. Curr. Org. Chem., 17: 853-870.

E 1 m or e J.S., M o t tra m D.S., En s e r M., Wo od J.D. (2000). The effects of diet and breed on the volatile compounds of cooked lamb. Meat Sci., 55: 149-159.

G ą s i or R., Wo j t y c z a K. (2016). Sense of smell and volatile aroma compounds and their role in the evaluation of the quality of products of animal origin - a review. Ann. Anim. Sci., 16: 3-31.

Ins a ust i K., B eria in M.J., Gorraiz C., Purroy A. (2002). Volatile compounds of raw beef from 5 local Spanish cattle breeds stored under modified atmosphere. J. Food Sci., 67: 1580-1589.

K ang G., Cho S., S e ong P., P ark B., K i m D., K i m Y., K ang S., P a rk K. (2013). Effects of high pressure processing on fatty acid composition and volatile compounds in Korean native black goat meat. Meat Sci., 94: 495-499.

$\mathrm{K}$ a r a b a g i a s I.K. (2018). Volatile profile of raw lamb meat stored at $4 \pm 1{ }^{\circ} \mathrm{C}$ : The potential of specific aldehyde ratios as indicators of lamb meat quality. Foods, 40: doi:10.3390/foods7030040.

Karpiński P., Łą t k ow ska M., Kruszewski B., Kuźma P., Obiedzińs ki M.W. (2015). Profile of volatile compounds in European dry-cured hams as indicator of their quality and authenticity (in Polish, with English summary). Zywn-Nauk. Technol. Ja., 2: 47-61.

Kaw ęcka A., S os in-Bzduch a E., Puchała M., S i k or a J. (2017). Effect of maize DDGS addition on carcass and meat quality of lambs of native sheep breed. J. Appl. Anim. Res., 46, 1: 1-5.

$\mathrm{K}$ i e fl J., S c h i e b e r le P. (2013). Evaluation of process parameters governing the aroma generation in three hazelnut cultivars (Corylus avellana L.) by correlating quantitative key odorant profiling with sensory evaluation. J. Agric. Food Chem., 61: 5236-5244.

K i m Y.H., N a m K.C., A h n D.U. (2002). Volatile profiles, lipid oxidation and sensory characteristics of irradiated meat from different animal species. Meat Sci., 61: 257-265.

Lee E.J., L ove J., A hn D.U. (2003). Effect of antioxidants on consumer acceptance of irradiated turkey meat. J. Food Sci., 68: 1659-1663.

L or en zo J.M., Fra n c o D., C a r b a 11 o J. (2014). Effect of the inclusion of chestnut in the finishing diet on volatile compounds during the manufacture of dry-cured "Lacón" from Celta pig breed. Meat Sci., 96: 211-223.

L v S.D., Wu Y., S ong Y.Z., Zh ou J.S., L i a n M., Wang C., L i u L., M en g Q.X. (2015). Multivariate analysis based on GC-MS fingerprint and volatile composition for the quality evaluation of $\mathrm{Pu}$-erh green tea. Food Anal. Methods, 8: 321-333.

Machiels D., van Ruth S.M., P os thumus M.A., I s t a s s L. (2003). Gas chromatographyolfactometry analysis of the volatile compounds of two commercial Irish beef meats. Talanta, 60: $755-764$.

Madruga M.S., Arruda S.G., Narain N., S ouza J.G. (2000). Castration and slaughter age effects on panel assessment and aroma compounds of the "mestiço" goat meat. Meat Sci., 56: $117-125$. 
Madruga M.S., Elmore J.S., Oruna-Concha M.J., Balagiannis D., Mottram D.S. (2010). Determination of some water-soluble aroma precursors in goat meat and their enrolment on flavor profile of goat meat. Food Chem., 123: 513-520.

Majcher M.A., Kaczmarek A., Klensporf-Pawlik D., Pikul J., Jeleń H.H. (2015). SPME-MS-based electronic nose as a tool for determination of authenticity of PDO cheese, oscypek. Food Anal. Methods, 8: 2211-2217.

Marne y L.C., S i e g l e r W.C., P ars on s P.A., Hoggard J.C., Wright B.W., S y nove c R.E. (2013). Tile-based Fisher-ratio software for improved feature selection analysis of comprehensive two-dimensional gas chromatography-time-of-flight mass spectrometry data. Talanta, 115: 887-895.

$\mathrm{N}$ a m K.C., A h n D. (2003). Combination of aerobic and vacuum packaging to control lipid oxidation and off-odor volatiles of irradiated raw turkey breast. Meat Sci., 63: 389-395.

Narváez-Rivas M., Gallardo E., Ríos J.J., León-Camacho M. (2010). A tentative characterization of volatile compounds from Iberian dry-cured ham according to different anatomical locations. A detailed study. Grasas Aceites, 61: 369-377.

N arvá ez-Rivas M., P a b los F., Jurado J.M., L é n - C a m a c ho M. (2011). Authentication of fattening diet of Iberian pigs according to their volatile compounds profile from raw subcutaneous fat. Anal. Bioanal. Chem., 399: 2115-2122.

Nicolotti L., Cordero C., Cagliero C., Liberto E., Sgorbini B., Rubiolo P., Bicc hi B. (2013). Quantitative fingerprinting by headspace - Two-dimensional comprehensive gas chromatography-mass spectrometry of solid matrices: Some challenging aspects of the exhaustive assessment of food volatiles. Anal. Chim., 798: 115-125.

Nowicka K., Jaworska D., Przybylski W., Górska E., Tambor K., Półtorak A. (2017). Determinants of the sensory quality of półgęsek in relation to volatile compounds and chemical composition. Pol. J. Food Nutr. Sci., 67: 283-292.

Nuernberg K., Wo od J.D., S c olla n N.D., Ri c hard s on R.I., N u t e G.R., N u e rn berg G. (2005). Effect of a grass-based and a concentrate feeding system on meat quality characteristics and fatty acid composition of longissimus muscle in different cattle breeds. Livest. Prod. Sci., 94: $137-147$.

Pongsetkul J., B enjakul S., Sumpavapol P., Os ako K., Faithong N. (2016). Properties of salted shrimp paste (Kapi) from Acetes vulgaris as affected by postmortem storage prior to salting. J. Food Process. Preserv., 40: 636-646.

Resconi V.C., Campo M.M., Montossi F., Ferreira V., Sañudo C., Escudero A. (2010). Relationship between odor-active compounds and flavor perception in meat from lambs fed different diets. Meat Sci., 85: 700-706.

Rivas-Cañedo A., A pele o E., Muiño I., Pérez C., Lauzurica S., Pérez-Sant a e s c olást ic a C., Díaz M.T., Cañeque V., F u en te J. (2013). Effect of dietary supplementation with either red wine extract or vitamin $\mathrm{E}$ on the volatile profile of lamb meat fed with omega-3 sources. Meat Sci., 93: 178-186.

Scollan N., Richardson I., Moloney A., Dannenberger D., Hocquette J.F., Nue rnberg K. (2006). Innovations in beef production systems that enhance the nutritional and health value of beef lipids and their relationship with meat quality. Meat Sci., 74: 17-33.

Sh a hidi F. (Ed.) (1994). Flavor of Meat and Meat Products 1st edition. Springer-Science+Business Media, B.V., Salisbury, UK. pp. 12, 15, 39, 178, 184, 226, doi: https://doi.org/10.1007/978-1-46152177-8 (retrieved June 17, 2019).

S on c in S., Chi es a L.M., C ant on i C., B i ond i P.A. (2007). Preliminary study of the volatile fraction in the raw meat of pork, duck and goose. J. Food Compos. Anal., 20: 436-439.

Stanimirova I., Üstün B., Cajka T., Riddelova K., Hajslova J., Buydens L.M., Wa lczak B. (2010). Tracing the geographical origin of honeys based on volatile compounds profiles assessment using pattern recognition techniques. Food Chem., 118: 171-176.

Vas ta V., R a tel J., Engel E. (2007). Mass spectrometry analysis of volatile compounds in raw meat for the authentication of the feeding background of farm animals. J. Agric. Food Chem., 55: 4630-4639.

Received: 19 IX 2019

Accepted: 27 V 2020 